\title{
Colorectal Cancer by AJCC v6 Stage
}

National Cancer Institute

\section{Source}

National Cancer Institute. Colorectal Cancer by AJCC v6 Stage. NCI Thesaurus. Code C90506.

A term that refers to the staging of colorectal carcinoma according to the American Joint Committee on Cancer, 6th edition. 